\title{
Relationship between mean platelet volume and retinopathy of prematurity
}

\author{
Umit Yolcu $^{1}$ - Demet Y. Civan ${ }^{2}$
}

Received: 11 May 2015 / Accepted: 2 June 2015 / Published online: 9 June 2015

(C) Springer-Verlag Berlin Heidelberg 2015

\section{Dear Editor;}

We congratulate Tao et al. [1] for their study entitled 'Relationship between mean platelet volume and retinopathy of prematurity'. The authors investigated the association between mean platelet volume (MPV) and the occurrence of type 1 retinopathy of prematurity (ROP) by sampling the peripheral blood platelet indices 1 week prior to laser surgery. They concluded that elevated MPV is associated with the occurrence of type 1 ROP. We think that this is an important finding explaining the role of platelets in the development of ROP, and we would like to express our reservations about the study.

It is known that preterm infants have an increased risk of developing some morbidities such as necrotizing enterocolitis (NEC), bronchopulmonary dysplasia (BPD), and intraventricular hemorrhage, as well as than ROP. Dani et al. investigated the relation between MPV and the occurrence BPD, and they reported that high MPV is an independent risk factor for the development of

Umit Yolcu

umit_yolcu@hotmail.com

1 Ophthalmology Service, Sarıkamış Military Hospital, Sarıamıs, Kars 36500, Turkey

2 Ophthalmology Service, Mersin State Hospital, Mersin, Turkey
BPD [2]. They also found that the development of ROP is significantly high in the BPD group. Miner et al. investigated the factors affecting the severity of NEC and reported that higher MPV values are associated with the development of higher grade NEC [3]. However, Tao et al. included in the study premature infants that developed ROP and healthy premature infants, but they did not apply any exclusion criteria for the subjects.

It is known that morbidities of premature infants such as NEC and BPD last long or develop around the gestational age of 33-34 weeks, and we think that these conditions can affect the MPV values. We wonder whether the authors excluded the infants that have such morbidities, and if they did, after the exclusion, whether the difference in MPV is still significant.

Conflict of interest None of the authors have any conflict of interest with the submission.

\section{References}

1. Tao Y, Dong Y, Lu CW, Yang W, Li Q (2015) Relationship between mean platelet volume and retinopathy of prematurity. Graefes Arch Clin Exp Ophthalmol. doi:10.1007/s00417-015-2972-8

2. Dani C, Poggi C, Barp J, Berti E, Fontanelli G (2011) Mean platelet volume and risk of bronchopulmonary dysplasia and intraventricular hemorrhage in extremely preterm infants. Am J Perinatol 28:551556. doi:10.1055/s-0031-1274503

3. Miner CA, Fullmer S, Eggett DL, Christensen RD (2013) Factors affecting the severity of necrotizing enterocolitis. J Matern Fetal Neonatal Med 26:1715-1719. doi:10.3109/14767058.2013.798283 